\title{
What Sorts of Agglomerations Really Matter to Productivity?: A Regional Analysis of Europe's Manufacturing Sector
}

\author{
Bruno Bracalente, Cristiano Perugini, and Fabrizio Pompei*
}

ABstract. The objective of this paper is to analyze the effects on regional manufacturing productivity of various external factors that characterize the economic, social, and institutional environments to which they belong. We define and distinguish here between homogeneous and urban heterogeneous external economies. Hypotheses of the existence and co-existence of the two types of external effects are formulated and tested for six manufacturing subsectors of the regions of 13 western EU countries from 1995 to 2004. Although the available data are far from optimal, the empirical analysis that they enable provides various insights that partly corroborate our conjectures. In particular, the results supply evidence of the generalized beneficial effects of urban heterogeneous agglomeration. They also reveal the complexity and sector-specificity of the effects of industry specialization patterns.

JEL classification: J.24, O.14, O.18

Keywords: homogeneous external economies, urban heterogeneous external economies, manufacturing productivity, agglomeration, EU regions

\section{INTRODUCTION}

Aspects related to competitiveness and productivity at regional level have increasingly been a focus of scholarly activity for some time, as evidenced by the large theoretical and empirical literature now available. In Europe, this interest has been significantly stimulated by policy concerns regarding productivity growth and the reduction in spatial differences in interregional competitiveness. The remarkable geographical disparities in both competitiveness and local economic growth rates are indeed persisting features Europe's economy, which not only interfere with cohesion objectives of the Union, but also jeopardize its various crucial achievements (e.g., the monetary union) and future developments (e.g., enlargement).

The aim of this paper is to shed light on the effects exerted on productivity dynamics by various external factors that characterize the economic, social and institutional environments to which they belong. These factors have been widely debated in the literature, which has in some cases opposed external economies stemming from industry agglomeration to those deriving from industry diversification, typical in urban settings. We intend to contribute to this debate first of all by highlighting the ambiguity of identifying the variety of economic activity associated with urbanization economies. We contend that diversity of economic activity (i) is not an attribute exclusive to urban settings; (ii) is only one among various other urban sources of external economies; and (iii) is not necessarily an alternative to specialization. We then distinguish and define two groups of external economies-

\footnotetext{
* Bruno Bracalente is Full Professor, and Cristiano Perugini and Fabrizio Pompei are Researchers at the Department of Economics, University of Perugia.

Contact information: Cristiano Perugini, Department of Economics, Finance and Statistics, University of Perugia, Via Pascoli 20, 06123 Perugia, Italy. E mail: perugini@unipg.it.
}

(C) Southern Regional Science Association 2010. 
homogeneous and urban heterogeneous - and empirically test their existence, co-existence, and impact on the dynamics of regional labor productivity in manufacturing. The empirical analysis covers six manufacturing subsectors and 151 NUTS2 regions belonging to 13 countries of the old EU from 1995 to 2004. It adopts panel data techniques to address possible threats to the reliability of outcomes, in particular those due to the temporal and geographical persistence of productivity growth and to endogeneity of explanatory variables. Since the data available for the geographic and time scopes considered here are far from optimal for the hypotheses tested, outcomes should be considered preliminary only and supporting prospects of future research.

Since the existing theoretical background on these topics is very rich and diversified, Section 2 is limited to a discussion of the streams of literature most relevant to the aims and scope of this paper. Section 3 presents the methods and results. It starts (3.1) by describing the paper's general objectives and the constraints posed by data availability: it then explicitly renders the hypotheses we intend to test. Sections 3.2 and 3.3 describe the indicators we use and comment on some descriptive statistics, respectively. Section 3.4 presents the empirical model, econometric approach, and the results. Section 4 briefly summarizes the outcomes and concludes with some final remarks.

\section{THEORETICAL FRAMEWORK}

Specific characteristics of regional contexts exist that affect productivity and, thus, the competitiveness of firms located there. This is a well-established concept in regional science that has been widely debated and that also has been illustrated both theoretically and empirically. We focus here on specific strands of this literature that are more pertinent to and consistent with our approach which, in line with the classical works by Hoover $(1937,1948){ }^{1}$ distinguishes between homogeneous and urban heterogeneous external economies as well as the relationships between them.

\subsection{Homogeneous External Economies}

The level and dynamics of labor productivity in a region depend on many factors: the region's economic structure, its propensity for generating innovative activity, its economic openness, the endowment of skills owned by its residents, the density of decision centers that it contains, and the environmental, social, and cultural milieu it embraces (Gardiner, Martin, and Tyler, 2004). Many of these factors are explicitly considered because of their dynamic implications (i.e., on the evolution of productivity over time), which are also the bases for alternative explanations of convergence, divergence or persistence of productivity disparities. In the standard neo-classical model, the focus is on capital endowment per worker and on the rate of technical change assumed exogenous. This point is well-known to be the essential difference with respect to endogenous growth models, in which the rate of technological progress depends on the growth process itself, by means of various channels that introduce the crucial importance of agglomeration factors (e.g., the number of knowledge workers and the size of the knowledge and technology base). In this case, regional productivity disparities are determined by the localization of these technology/knowledge factors, whereas their persistence or degradation depends on their dispersion intensity and speed. These dynamic knowledge spillover effects may typically derive from (and take place in) the agglomeration of similar or related production activities, which have been introduced into a wider set of localization external effects called MAR externalities by Glaeser et al. (1992). These include

\footnotetext{
1 These works may be considered the first attempt of classification of external agglomeration economies, distinguished into: (a) economies external to firms but internal to the sector (localization economies); and (b) economies external to firms and to the sector but internal to the urban area (urbanization economies).
} 
both static (Marshall, 1920) and dynamic (Arrow, 1962; Romer, 1986) agglomeration economies. During the last 15 years, the role of static Marshallian agglomeration effects has been developed in various directions largely as localization externalities within the framework of the "new economic geography" (NEG) (Krugman, 1991a, 1991b). NEG emphasizes the role of the accumulation of specialized labor pools and the agglomeration of the suppliers of services and other inputs specific to an industry, not just the relative efficacy of its knowledge exchange. In particular, the specific point of static and dynamic knowledge and innovation effects on the performances of closely co-located firms has been the object of very extensive literature from various theoretical perspectives (e.g., Audretsch, 1998; Jaffe, Trajtenberg, and Henderson, 1993; Audretsch and Feldman, 2004; John and Pouder, 2006).

This simplified theoretical basis may be enriched from several points of view. For example, Glaeser et al. (1992) stress via the MAR externality framework that a single firm (spatial monopoly) should be more efficient than a set of perfectly competitive firms when an industry is spatially concentrated. This is because monopolies can better restrict the leakage of ideas, which allows a fuller internalization of any inherent externalities. Conversely, Porter's (1990) "competitive advantage" highlights how local competition may be good for productivity growth, since it fosters the search for and rapid adoption of innovations. Regardless, industry specialization is crucial for productivity growth, but only it only specifies specialization as a cluster of economic activity within a limited geographic space.

The sources of external economies effected by the NEG and competitive advantage may be further widened by recalling the neo-Marshallian approach. This approach, which historically emanates from the notion of industrial districts, instigated much of the theoretical and empirical work that underlies the "local development" approach (e.g., Becattini, 2004; Cossentino, Pyke, and Sengerberger, 1996). Of particular interest from the literature on local development is that external economies need not be produced by the clustering of economic activity at a single location-identified by Bellandi (2004) as the "local production system"- but may also be features of the local society. Thus external economies can be a function of both a local production system and the local society's broader social, cultural, and institutional milieu, which, in turn, can interact with and be influenced by the production system. That is these societal features can be crucial to local firms' competitiveness. For example, such societal features can facilitate social interactions that may lower costs of market entry or market transactions, favor knowledge flows, or resolve common problems (Guiso and Schivardi 2007). So, as proposed by Becattini and Musotti (2003) for the specific case of the industrial district, the sources of competitive advantage external to firms may be distinguished into two groups: those that depend on the presence of a cluster, and those emerging from its interactions with the local context. The former tend to be affiliated with external economies of (i) organization, (ii) knowledge (contextual) and learning, and (iii) concentration, and the latter with (i) training, (ii) transaction, and (iii) adaptation.

We call this broad set of localization externalities "homogeneous economies" to denote how, under certain conditions, they stem from the presence of one (or a few integrated) manufacturing sector's specializations. Of course, depending on the intrinsic sectoral features (first of all the importance of economies of scale), regional sectoral specialization may result either from the presence of a few large firms or from the concentration of several small- and medium-sized ones. As discussed above, in either case we may expect sectoral agglomeration economies to be at work: in the first case (a few large firms) where internal increasing returns to scale and basic MAR externalities are at work; in the second, where economies of scale are relatively less important, but co-location is encouraged by a mix of interfirm cooperation and competition as explained in the literature on clusters and industrial districts. 


\subsection{Urban Heterogeneous External Economies}

Jacobs $(1969,1984)$ concepts of variety and diversity are often contrasted with those on sectoral agglomeration. She contends that a geographically proximate but diverse set of economic activities are able to promote innovation since knowledge and idea flows spill over more freely across somewhat related industries (Frenken, Van Oort, and Verburg, 2007; Boschma and Iammarino, 2007). The focus here is exclusively on knowledge and innovation and supports a view that the most important inputs of knowledge come from outside of the region's core industry. A precondition for cross-fertilization of sticky knowledge (Von Hipple 1994) is social interaction. Intense and diverse interaction is most prevalent in cities, since their economies are both geographically compact and economically diversified: as a result, it is there that interpersonal contact is also both diverse and frequent.

Jacobs also suggested that by fostering innovative activities diversity should lead to economic growth. Lucas (1988) articulated this best in emphasizing that increasing returns to resource agglomeration are related to the geographically compact nature of cities. It is this spatial compactness that facilitates communications, which in turn makes these locations more competitive. The identification of product diversity within urban settings has led a number of researchers to define Jacobs's diversity concept as intrinsic to "urbanization externalities" and accordingly applied various indices of urban size to measure them. Others have measured Jacobian externalities using various kinds of industry diversity/concentration indices (e.g., Glaeser et al., 1992; Harrison, Maryellen, and Kelley, 1996; Feldman and Audretsch, 1999; Duranton and Puga, 2001; Paci and Usai, 1999; Cingano and Schivardi, 2004). However, this latter set of indices introduces some ambiguity for at least three reasons: (a) economic diversity is not an attribute exclusive to urban settings; (b) the diversity of economic activities is only one among various other characters of urban areas and it also may be a source of other external economies, as emphasized by extensive urban literature; and (c) diversity is not necessarily alternative to specialization. We investigate each of these in turn below.

\section{(a) Diversity is not only urban}

Rural (non-urban) systems have tended to evolve from economies dominated by farming and farming-related activities towards more diversified settings: in some rural economies, agriculture has even come to play a minor role. This evolutionary process can be accelerated and accentuated by urban congestion and other urban "bads," which can induce productive activities to relocate outside urban areas (see also point b below). Diversified rural economies have been connected to a viable, dense social network (Fuà, 1988) governed by a shared, historically rooted institutional setting (e.g., prevalence of informal relationships, crucial role of the household, and attitudes of cooperation inherited from pastoral tradition) both of which promote efficient and effective exchange of information and knowledge (Martino and Perugini, 2007; Murdoch, 2000). The lower spatial density of economic activity and lower intensity of information and knowledge flows compared with those of urban settings (see point c), however, weaken the possible impact of the idea of cross-fertilization as a basis for economic growth through external economies of variety in a rural setting. The main point to glean here is that economic diversity is not exclusive to urban areas, so a simple measure of related diversity alone (i.e., not associated to measures of other urban assets or features) cannot be a good proxy for urban heterogeneity effects.

(C) Southern Regional Science Association 2010. 


\section{(b) Diversity is one among various other sources of urban external economies}

The centrality of knowledge and information flows due to diversity of related economic activities is emphasized in the literature, but within a more complex framework of "urban assets" (e.g., Hoover, 1937; Glaeser et al., 1992; Turok, 2004; Henderson, 2007), such as skilled labor pools (e.g., Wheeler, 2005; Rauch, 1991), sustained and diversified local demand (e.g., Henderson, 1986; Tabuchi and Yoshida, 2000), presence of public and private research and education centers, institutional networks (Turok, 2004), proximity to decision centers (Ades and Glaeser, 1995), proximity to advanced, nonsector-specific business services (Kolko 1999), and the availability and efficiency of hard and soft infrastructure (Davis and Henderson, 2003). Thus, urbanization economies comprise more than just the variety of economic activities. Hence, a single sectoral concentration/diversity measure is likely to be an unsatisfactory proxy for them. Moreover, not all urban areas contain the same urban assets. For instance, depending on various factors (e.g., development stage and model), a service-based economy may depend on the strong presence of public administration as opposed to advanced business services; the abundance of specific types of human capital (say, e.g., science and technology versus arts and humanities) can encourage the development and performance of very different types of firms. This means that a satisfactory measure of urban externalities cannot be a simple urban indicator (i.e., population density as a proxy for density of economic activity, and thus diversity). Instead, it must adequately integrate with others to properly represent the existence and strength of a variety of key urban economic features.

\section{(c) Diversity and specialization may co-exist}

As mentioned above, Jacobian externalities generally are assumed to oppose specialization externalities (e.g., Feldman and Audretsch, 1999) in the sense that "diversity increases as the measure of specialization decreases" (Ejermo, 2005, p. 171). However, a number of theoretical and empirical contributions consider their co-existence. Within the NEG framework, the co-existence of diversity and specialization is explained via the demand side of the market (Fujita and Thisse, 2002). Product variety enters consumers' utility functions in a basic two-region (core-periphery) model, in which the concentration of labor (and, hence, of consumers) in the core creates a strong local demand for a diversified set of final products. Hence, agglomerative effects tend to take place in the core for several industries. This in turn gives rise to the clustered co-existence of specialized activities there. The same outcome can occur if production processes are decomposed into different phases and carried out by a system of sub-contractors. Consumers' demand for variety increases the diversity of requests for subcontractors by final firms. The strong demand for each specific product generates a cluster of specialized (phase) producers via typical agglomeration processes. Together concentrated consumer demand and externalities gained through agglomeration enable the production of great variety of products. In this sense, "specialization implies diversity" (Ejermo, 2005, p.170).

The same outcome can be explained via product life-cycle theories in a hierarchy of cities, which may be considered as new-product nurseries where ideas tend to be generated, as formalized by Duranton and Puga (2001). Larger cities can have considerable congestion costs, which induce firms to maintain only those tasks that most benefit, directly or indirectly, from contact with final demand or strategic flows of information (e.g., R\&D, new product development and launch, and high finance), while shedding (decentralizing) other activities to the periphery. Thus, large urban regions (i.e., regions with a very important urban center or a metropolitan area) may be characterized by both the presence of marked economic diversity and by specialized economic clusters (in peripheral areas). Similarly, in 
regions with various small- and medium-sized cities, where congestion costs are lower, "urban" firms may also retain mass production processes and, depending on the size of the sectors, also generate a similar co-existence of diversity and specialization. This possibility has been acknowledged empirically in many contributions, as witnessed by the widespread contemporaneous use of sector specialization (localization, usually concentration) and diversity indexes to explain, for example, employment growth (e.g., Glaeser et al. 1992), innovation activities (e.g., Harrison, Maryellen, and Kelley, 1996; Paci and Usai, 1999; Van Ort, 2002; Cingano and Schivardi, 2004), and productivity growth (e.g., Cingano and Schivardi, 2004).

Taken together, points a, b, and c support the idea that homogeneous and urban and heterogeneity externalities are not mutually exclusive, since they basically emerge from different, potentially co-existing conditions. The former are sector-specific (homogeneous) and take place within a single industry; the latter (urban heterogeneous) are not sectorspecific and take place within a variety of interconnected sectors located in urban areas able to enrich the set of favorable productive situations. In essence, then, while agglomerations of firms can be part of urban areas, the agglomeration need not conflict with Jacobian notion of urban diversity. This is especially true if the agglomeration, as often happens, is in a manufacturing sector that is in structural decline in both absolute and relative terms; in such contexts, more space may actually be available for the localization of other activities. Present evidence of this may be found in the textile and clothing district of Prato, Tuscany, where a strong agglomeration of firms is located in a urban area (Prato's metropolitan area is now largely indistinguishable from Florence's). Similarly, in the Emilia Romagna region, many industrial districts and clusters co-exist within a dense network of medium and medium-large towns and cities.

\section{EMPIRICAL ANALYSIS}

This part of the paper presents the empirical analysis based on the theoretical framework discussed above. Section 3.1 specifies the main objective of the analysis, renders explicit the hypothesis we intend to test empirically, and illustrates the constraints posed by

data. Section 3.2 defines the indicators used in the analysis. Then we present some descriptive statistics (Section 3.3) and discuss the econometric approach and results (Section 3.4).

\subsection{Objectives, hypotheses and data constraints}

The general objective of the empirical analysis is to estimate the influence of homogeneous economies and of urban heterogeneous external economies on regional productivity growth in Europe in six manufacturing subsectors. On the basis of the theoretical arguments proposed in the previous sections, we test the following hypotheses:

$H_{1}$ : a growing regional specialization in a manufacturing subsector is beneficial to its productivity growth and this effect is reinforced in the subsectors that favor the division of labor between local firms;

$\mathrm{H}_{2}$ : stronger related diversity and urban assets foster productivity growth of the region (urban heterogeneity external economies) and these effects may co-exist with those deriving from sectoral agglomeration.

Various constraints posed by data availability significantly influence the capacity of our analysis to properly capture the aspects considered. This is accounted for when we interpret results.

(C) Southern Regional Science Association 2010. 
A crucial aspect regards the choice of the geographic unit of analysis, since the objective of considering regions of various EU countries necessarily indicates the use of NUTS2 regions. Apart from remarkable differences in terms of the relative size of these regions, they are clearly too large to allow certain types of external economies to be captured correctly. Some externalities of the homogeneous type typically occur in territories where the local production system is located, which is normally part of a NUTS2 region. So smaller spatial units such as functional economic regions identified as travel-to-work areas (TTWA), which would account for systemic features that may characterize specific local societies and local production systems, might have been preferred (Paci and Usai, 1999, 2006; Perugini and Daddi, 2005). Unfortunately, TTWA are available only for a limited set of Western EU countries, for which little data are available. Similarly, scant data are available at regional NUTS3 level. However, the choice of the NUTS2 level does allow us to consider the widest coverage of European regions with the acceptable availability of data needed to define dependent and explanatory variables.

The geographic coverage of the analysis is greatly limited by the sectoral breakdown of the variables considered. Data on value added and employment are drawn from the Cambridge Econometrics (CE) dataset, which provides a breakdown into six manufacturing subsectors $^{2}$ only for the 151 regions of 13 members of the EU before 2004 (all the old EU-15 countries, excluding Germany and Austria). ${ }^{3}$ Data are available from 1995 to 2004.

Lastly, the level of sectoral breakdown itself is only partially able to depict the sector specificities needed for a proper study of the aspects considered here. Each of the six manufacturing subsectors includes very different activities, often characterized by diverging organizational patterns. This limitation is then exacerbated by the lack of data on average firm size (or distribution by size of firm by sector and region). For these reasons, the empirical evidence provided here should be considered as preliminary. Our hope is that it will instigate future studies with empirical materials more suitable to our research focus.

\subsection{Definition of indicators}

3.2.1. Dependent variable. We move here from the standard classical concept of labor productivity, which is consistent with the theoretical perspective adopted and places productivity differentials in the framework of productivity growth/convergence patterns. We do not discuss here the problem of identifying or distinguishing the concepts of competitiveness and productivity, which are discussed in depth in many other contributions (e.g., Begg, 2002; Gardiner, Martin, and, Tyler, 2004; Krugman, 1990; Porter, 2003).

Our starting point is a classical indicator of labor productivity (value added per employee). In order to consider the role played by differences in working times, we correct this indicator using the data supplied by the Groningen Growth and Development Center (GGDC) 60 industries database (version October 2005). This database includes information on the number of hours worked per employed person by sector and country. So, subnational working-time differences are not taken into account, but most of them are likely to be

\footnotetext{
2 The subsectors are: DA (Food, beverages and tobacco); DB+DC (Textiles and leather, etc.); DF+DG+DH (Coke, refined petroleum, nuclear fuel and chemicals, etc.); DL (Electrical and optical equipment); DM (Transport equipment); and DD+DE+DN+DI+DJ+DK (Other manufacturing).

${ }^{3}$ Due to missing data on economic accounts, the following regions had to be excluded from the sample: two Spanish regions, ES63 - Ciudad Autonoma de Ceuta and ES64 - Ciudad Autonoma de Melilla; two Portuguese, PT2 - Região Autónoma dos Açores and PT - 3 Região Autónoma da Madeira; and four French overseas regions (FR91, 92, 93, 94). Four other regions (GR41 - Voreio Aigaio; UKd1 - Cumbria; UKf3 - Lincolnshire; UKm2 - Eastern Scotland) were excluded due to missing data on patents. A few other missing data for other regions were estimated by means of linear interpolation.
} 
captured by national legislation and norms. Thus, for each manufacturing subsector, we use the following indicator of hourly labor productivity: ${ }^{4}$

$$
\operatorname{PROD}_{\mathrm{r}, \mathrm{h}}=\frac{V_{\mathrm{r}, \mathrm{h}}}{L_{\mathrm{r}, \mathrm{h}} \cdot H W_{c, h}},
$$

where $V_{\mathrm{r}, \mathrm{h}}$ is $L_{\mathrm{r}, \mathrm{h}}$ are the value added (in 1995 constant prices) and employment (number of employees) in manufacturing subsector $h$ for region $r$, respectively. $H W_{\mathrm{c}, \mathrm{h}}$ are the hours yearly worked per employees in manufacturing subsector $h$ for country $c$, and is obviously common to all the $r$ regions belonging to each country. To compare productivity between countries correctly, value added in Euros at constant prices was converted into purchasing power parities (PPPs) by applying the 1995 conversion factor derived from GDP. ${ }^{5}$

3.2.2. Homogeneous external effects. In order to account for the importance the manufacturing sector as a whole, we use the following Balassa specialization index (employment location quotient) for each manufacturing subsector:

$$
\operatorname{SPEC}_{r, h}=\frac{L_{r, h} / L_{r, M}}{L_{e u, h} / L_{e u, M}},
$$

where $L_{\mathrm{r}, \mathrm{h}}$ and $L_{\mathrm{r}, \mathrm{M}}$ are employment in manufacturing subsector $h$ and total manufacturing in region $r$, respectively. $L_{\mathrm{eu}, \mathrm{h}}$ and $L_{\mathrm{eu}, \mathrm{M}}$ are the corresponding measures for the aggregate of EU countries considered. One possible weakness of this measure is that it may give undue importance to particular industries in regions with very small manufacturing sectors. For this reason, we also introduced as a control variable a measure of all manufacturing employment to total employment (SPEC_m, see Section 3.2.4). Therefore, SPEC is a measure of homogeneous agglomeration patterns and does not include the degree of manufacturing dependency which normally characterizes lagging regions.

Unfortunately, no information is available on the average size of manufacturing firms or on the distribution of firms by size classes. Eurostat data on the number of local units are in fact largely incomplete at regional level. Specialization levels being equal, this information would be important in order to distinguish between regions characterized by the presence of the manufacturing concentration of medium and small firms or by only one/a few large firms. However, these features can be partly deduced from sectoral specificities.

3.2.3. Urban heterogeneous effects. Given the available data, we were able to consider three indicators to measure the sources of urban heterogeneity external economies. The first is residential density, a commonly employed indicator of urbanization (OECD, 1994). Given the size of some of our geographic units of reference (NUTS2 regions), a simple indicator of population density (regional population over regional area) seemed somewhat inappropriate since, for example, the average regional density is equal for two regions, one of them with a very highly urbanized area and large rural spaces, and the other with a plurality of mediumsized towns. Nevertheless, in the second case the advantages associated with the urban effect are gained by a larger share of manufacturing firms, whereas diseconomies of congestion are less important. To capture this "diffused" urban effect, we propose here the weighted

\footnotetext{
${ }^{4}$ Where not strictly necessary we omit the subscripts for time $(t)$ but the indicators always cover the period 1995-2004.

${ }^{5}$ As regards sectoral productivity comparisons, in theory the sector-specific conversion factor should be applied (see, for example, Sørensen, 2001). However, since sectoral PPPs are not available, the same conversion factor was used for each industry.
} 
geometric average of NUTS3 population density to compute the corresponding NUTS2 urbanization index:

$$
D_{E N S}=\left[\prod_{j \in r}\left(\frac{P_{j, r}}{A_{j, r}}\right)^{A_{j, r}}\right]^{\frac{1}{A_{r}}},
$$

where $P_{j, r}$ and $A_{j, r}$ are population and area (in square kilometers), respectively, of the $j$ NUTS3 regions making up the $r$ NUTS2 region. ${ }^{6}$ This urbanization index represents a growing density of agents (on both sides of the market) and so is also able to measure a growing density of economic activities and thus an increased probability of exchanges of information and ideas. The indicator is typically (and also in this case) correlated with an industry structure specialized in services, both public and private. Of course, very high values of population density could correspond to various types of congestion costs (and diseconomies), thus producing inverse effects on productivity.

The second indicator is intended to measure the role of industry variety. As discussed in Section 2, diversity needs to be "qualified" in order to represent the kind of diversity that actually promotes knowledge and information spillovers (this is "related" variety) and should be distinguished theoretically and empirically from urbanization (Frenken, Van Oort, and Verburg, 2007). Recall, the available sector breakdown (six subsectors of manufacturing plus agriculture, construction and six services subsectors) imposes severe constraints on building a fully satisfactory measure. The concept of "related" diversity would imply consideration of all possible interrelated specific activities that could cross-fertilize one another, so that a very detailed sector breakdown of manufacturing and services would be necessary for proper analysis. Consistent with Frenken, Van Oort, and Verburg (2007) and considering the large aggregates of services available, we decided to use a diversity indicator calculated only within the manufacturing subsectors, thus assuming that beneficial cross-industry effects take place mainly within the manufacturing sector. Our measure of related diversity is thus the inverse of a classical Herfindal-Hirschman concentration index:

$$
D I V_{-} m_{r}=\frac{1}{\sum_{h=1}^{6} s_{h, r}^{2}},
$$

where $s_{h, r}$, is the share of employment in subsector $h$ on total manufacturing.

Lastly, in order to have a proxy of the concentration of scientific and technological knowledge that could prevail in urban areas, we used recent statistics released by Eurostat on Human Resources in Science and Technology (HRST) (Eurostat, on-line statistics). These data are available at regional level but enable no sector breakdown since many missing values exist in the detailed industry tables. The "occupation" subset of HRST, used here, includes the following categories of workers:

- professionals, i.e., workers whose main tasks require a high level of professional knowledge and experience in the fields of physical and life sciences, or social sciences and humanities;

\footnotetext{
${ }^{6}$ Compared with the arithmetic average (the classical NUTS2 density of the population), the geometric average of NUTS3 densities is always smaller, and the difference with respect to the former increases as the concentration of the population in a few NUTS3 areas increases, thus fulfilling the properties required by our indicator of urbanization of the NUTS2 region.
} 
- technicians and associated professionals, i.e., workers whose main tasks require technical knowledge and experience in one or more fields of physical and life sciences, or social sciences and humanities.

These types of occupations typically require successfully completed education at the third level, corresponding to the International Standard Classification Education (ISCED) levels 6, $5 \mathrm{a}$, and $5 \mathrm{~b}$. However, whether the people involved have or do not have this formal education is irrelevant, as those in these occupations are automatically considered as belonging to HRST. Therefore, the indicator captures not only the codified but also the tacit component of knowledge of highly skilled human resources. The indicator used is simply the ratio of Human Resources in Science and Technology "occupied" (HRSTO) on manufacturing employment, in order to represent the endowment or science and technology knowledge provided by the regional system to each manufacturing worker:

$$
H R S T_{r}=\frac{H_{R S T O}}{L_{r, M}},
$$

Of course, we should also take into account many other measures of urban assets (e.g., endowment of material infrastructures, etc.), but unfortunately pertinent regional-level data were not available at an acceptable level of completeness.

Since the three indicators do not necessarily co-exist in urban areas (for instance, not all densely populated areas are endowed with high HRST), we considered them separately as determinants of productivity growth. However, in order to verify if the co-existence of high levels of the three possible sources (high urbanization together with high related variety and high HRST) benefits productivity, we also considered in the econometric analysis a dummy variable $\left(H E T \mathrm{~d}_{\mathrm{r}}\right)$, which is 1 for regions in which all three variables are above the $66^{\text {th }}$ percentile, and 0 otherwise. (The threshold was inevitably arbitrary and was chosen so an adequate number of regions associated with the value 1 was possible.)

3.2.4. Control Variables. Included for the reasons explained in Section 3.2.2, the first control variable is the manufacturing sector's employment location quotient:

$$
\text { SPEC_ } \mathrm{m}_{\mathrm{r}, \mathrm{h}}=\frac{\mathrm{L}_{\mathrm{r}, \mathrm{M}} / \mathrm{L}_{\mathrm{r}, \mathrm{T}}}{\mathrm{L}_{\mathrm{eu}, \mathrm{M}} / \mathrm{L}_{\mathrm{eu}, \mathrm{T}}},
$$

where $L_{\mathrm{r}, \mathrm{M}}$ and $L_{\mathrm{r}, \mathrm{T}}$ are employment in manufacturing and total employment in region $r$, respectively. $L_{\mathrm{eu}, \mathrm{M}}$ and $L_{\mathrm{eu}, \mathrm{T}}$ are the corresponding measures for the aggregate of EU countries considered.

A major question is posed by the availability of a measure of private capital stocks at regional/sectoral level. Capital stocks are usually estimated from investment data if the latter have an adequate level of breakdown (the minimum required in order to take into account differences in depreciation rates is into investments in (i) land, sites, industrial buildings; and (ii) machinery, computers). The $\mathrm{CE}$ dataset supplies data on aggregate investments by manufacturing subsectors, but with no further qualitative distinction and for a relatively short time span (since 1980). Thus, the only option available is the calculation of regional gross capital stocks by manufacturing subsectors via a simplified version of the perpetual inventory method as applied to aggregate investments by subsectors, and assuming both a common working life (16 years) and simultaneous retirement. Given data availability on investments, this can be considered only a proxy of per employee physical capital endowment, calculated as:

(C) Southern Regional Science Association 2010. 


$$
C A P_{r, h}=\frac{K_{r, h}}{L_{r, h}}
$$

where $K_{\mathrm{r}, \mathrm{h}}$ is the proxy of the capital stock in region $r$ and subsector $h$.

As a third control we considered a proxy of innovation activity. Data on R\&D expenditures and personnel were largely unavailable at the regional level. Consequently, rather than measuring regional innovation activity by means of an input indicator, we used the output indicator, i.e., the number of patents $\left(P A T_{\mathrm{r}, \mathrm{h}}\right)$ registered at the European Patent Office (EPO) in each manufacturing subsector ${ }^{7}$ per thousand employees in the subsector:

$$
I N N_{r, h}=\frac{P A T_{r, h}}{L_{r, h}}
$$

The mechanisms and costs associated with a patent registration with the EPO signal that innovations measured are generally important from the economic point of view. ${ }^{8}$ The indicator may also be considered as a measure of high-level formalized knowledge endowment (typically employed in R\&D activities), i.e., able to generate important innovations, as opposed to the incremental innovations which are "invisible" to statistics and frequently emerge in specialized contexts, rich in tacit knowledge and learning by doing processes.

\subsection{Descriptive Analysis}

Table 1 shows the mean and coefficient of variation of regional labor productivity (PROD) and specialization (SPEC) for the 151 regions belonging to 13 original EU members, taken in the initial and final years of the study period (1995 and 2004). A common feature to all subsectors is the increase in both average levels and variability (an exception is Electronics) of $P R O D$. The highest values of average labor productivity in the final year available (2004) occurred in Fuel, Chemical, and Plastic Products and in Electronics. Conversely, the lowest value of labor productivity in the same year was recorded for Food, Beverages and Tobacco, the residual manufacturing subsector (Other Manufacturing) and in the Textile and Clothing sector (i.e., typically low value-added manufacturing industries). In all sectors, average productivity increased considerably in the ten-year period. It is noteworthy that Textile and Clothing exhibited the steepest growth (7.1 percent annual average). This performance may be attributed partly to problems generated by the use of non

\footnotetext{
${ }^{7}$ The reclassification of data on patents available in Eurostat Region into the six manufacturing subsector was carried out with the correspondence table provided by Schmoch et al. (2003).

${ }^{8}$ In recent years a large debate among scholars developed on the validity of patents as a proxy of innovative outputs. In particular Jaffe and Lerner (2004), focusing on the U.S case, stressed a positive correlation between an explosion of patent applications and a proliferation of inventions of dubious economic importance but which triggered costly litigations. The weakening of examination standards, caused by changes in the U.S. legal patent system in the last decades, is the main explanation of this pathology. The same authors warn that similar problems could affect legal patent systems of other developed countries in the future. In any case, they also acknowledge that, so far, "by and large, other countries have not made the same kinds of changes in their patent systems that the United States has made. Patents in Europe and Japan remain harder to get and there is less patent litigation. [...]" (Jaffe and Lerner, 2004, p. 6). However, other authors have highlighted the fact that the quality and economic value of patented innovations may be very heterogeneous (e.g., Harhoff et al., 1999) and propose replacing innovative indicators based on simple patent counts with measures based on citation frequencies and the number of nations in which patent protection is sought. For a recent discussion about possible indicators of patent quality and economic value, see van Zeebroeck (2007).
} 
sector-specific deflators. At the same time, the high value of the coefficient of variation also signals an increased and great variability among regional productivity.

The levels of specialization show that only in DA and DB-DC are average values far from the EU average. Over the period considered these averages remained substantially unchanged in four sectors, the exceptions being Textile and Clothing (decrease) and Transport Equipment (increase). Instead, an increase in dispersion of the levels of specialization was observed for all subsectors.

As regards the indicators of urban heterogeneous external effects (see Table 2), it is remarkable that the average values of DENS and DIV_m fell slightly between 1995 and 2004 . However, the very high (and increasing) values of the coefficient of variation for the first index indicate that the distribution of population among European regions is strongly polarized. The positive average dynamic of HRST clearly signals a growing average endowment of resources in science and technology available to labor units, accompanied by increasing regional dispersion.

Table 1. Mean and Coefficient of Variation of PROD and SPEC by Manufacturing Subsectors, 1995 \& 2004

\begin{tabular}{|c|c|c|c|c|c|c|}
\hline & $\begin{array}{l}\text { Food, } \\
\text { Beverages } \\
\text { \& Tobacco } \\
(D A)\end{array}$ & $\begin{array}{l}\text { Textiles \& } \\
\text { Clothing } \\
\text { (DB, DC) }\end{array}$ & $\begin{array}{l}\text { Fuels, } \\
\text { Chem., } \\
\text { Rubber \& } \\
\text { Plastic } \\
\text { Products } \\
\text { (DF-DH) }\end{array}$ & $\begin{array}{l}\text { Electrical \& } \\
\text { optical } \\
\text { equip. } \\
\text { (DL) }\end{array}$ & $\begin{array}{l}\text { Transport } \\
\text { Equipment } \\
(D M)\end{array}$ & $\begin{array}{l}\text { Other } \\
\text { Manufacturing } \\
(\mathrm{DD}, \mathrm{E}, \mathrm{N}, \mathrm{I}, \mathrm{J}, \mathrm{K})\end{array}$ \\
\hline & \multicolumn{6}{|c|}{ Labor productivity $(P R O D), \mathrm{PPP}, 1995$ prices } \\
\hline & 19952004 & 19952004 & 19952004 & 19952004 & 19952004 & 19952004 \\
\hline Mean & $26.94 \quad 34.50$ & 18.0933 .51 & $31.45 \quad 48.28$ & 30.4547 .29 & $23.66 \quad 37.14$ & 23.3133 .49 \\
\hline $\mathrm{Cv}$ & $0.29 \quad 0.61$ & $0.89 \quad 1.24$ & $0.35 \quad 0.73$ & $1.37 \quad 1.07$ & $0.31 \quad 0.66$ & 0.320 .93 \\
\hline \multicolumn{7}{|c|}{ Specialization $(S P E C)$} \\
\hline & $1995 \quad 2004$ & 19952004 & 19952004 & 19952004 & $1995 \quad 2004$ & 19952004 \\
\hline Mean & $1.26 \quad 1.25$ & $0.76 \quad 0.67$ & $1.04 \quad 1.02$ & $0.96 \quad 1.00$ & $\begin{array}{ll}0.99 & 1.08\end{array}$ & $1.00 \quad 1.00$ \\
\hline $\mathrm{Cv}$ & $0.56 \quad 0.70$ & $0.97 \quad 1.17$ & $0.49 \quad 0.54$ & $0.50 \quad 0.61$ & $0.73 \quad 0.99$ & $0.19 \quad 0.25$ \\
\hline
\end{tabular}

Table 2. Mean and Coefficient of Variation of DENS, DIV_m, and HRST, 1995 \& 2004

\begin{tabular}{lllllll} 
& \multicolumn{2}{c}{ Dens } & \multicolumn{2}{c}{ DIV_m } & \multicolumn{2}{c}{ HRST } \\
\hline & 1995 & 2004 & 1995 & 2004 & 1995 & 2004 \\
\hline Mean & 0.40 & 0.36 & 3.72 & 3.62 & 1.51 & 2.23 \\
$\mathrm{CV}$ & 2.47 & 2.69 & 0.16 & 0.17 & 0.47 & 0.68 \\
\hline
\end{tabular}

(C) Southern Regional Science Association 2010. 
In order to appreciate the changes in the shapes of the distribution of our key variables, we provide the K-density estimation in the initial and final years (Figures A1, A2 and A3 in the Appendix). In particular, Figure A1 displays a shift forward (corresponding to the discussed average increase) and, overall, a steady decrease in the estimated density of labor productivity values around the mean between 1995 and 2004. This clearly means that the variability of productivity performances increased (sigma divergence trend) across all sectors. All distributions are unimodal except that for the Fuels, Chemicals and Plastic sector (DF-DH), in which the bimodal character of the distribution in 1995 highlights the existence of two main clubs of regions (at productivity levels around 20 and 40 Euros per hour in PPP, respectively); in 2004, this dichotomy disappears and most regions shift towards the higher value. Distributions of regions according to specialization levels generally remain relatively unchanged over the period analyzed (see Figure A2). However, the position and shape of distributions are informative about the prevailing features of specific sectors: in textile and clothing and transport equipment regions are polarized between (many) unspecialized and (few) specialized ones. In the first case (DB_DC), this pattern strengthens during the study period and is consistent with that reported by Ezcurra et al. (2006). The remaining sectors show distributions relatively more concentrated around the EU specialization level, with a quite narrow shape for the residual sector (other manufacturing), which is consistent with the very low difference measured by the coefficient of variation. As expected, a very skewed and persistent distribution emerges in the case of DENS (see Figure A3), in which relatively few highly urbanized regions contribute towards generating a long right tail. As regards $D I V \_\mathrm{m}$, in the period considered the bimodal character of the distribution is mitigated and most European regions collect around its lower value. Remarkable changes also appear in the endowment of Human Resources in Science and Technology per manufacturing worker (HRST), for which the value around which most regions cluster shifts upwards.

\subsection{Econometric Analysis}

Econometric analysis aimed at testing the existence, direction and significance of the relationships between labor productivity growth in each manufacturing subsector $h$ and the set of explanatory variables. Within the family of econometric techniques for panel data our approach needed to consider various crucial aspects simultaneously.

First, extensive empirical evidence highlighted the strong time persistence of regional productivity patterns in Europe. This is confirmed here by the positive and statistically significant correlations in year-to-year productivity growth (around 0.3 for all sectors). This suggests that the dynamics of labor productivity may be, at least partly, explained by previous patterns, and this fact must be addressed in econometric estimates (via dynamic specifications) in order to avoid omitted variable biases.

Second, regional data are often characterized by spatial patterns, i.e., the behavior (or performance) of neighboring regions is somehow related. This spatial autocorrelation may basically be due to: (a) measurement errors for observations referring to contiguous geographic units; (b) actual spatial interaction patterns. Calculation of the Moran spatial autocorrelation index for productivity growth in our sample showed, consistently with other existing empirical evidence (see, for example, Benito and Ezcurra, 2005; Moreno et al., 2005; Bracalente and Perugini, 2009) significant and remarkable positive autocorrelation (Moran's I statistic is between 0.2 and 0.5 , depending on the sector and year considered; detailed data available upon request). These outcomes suggest that the spatial interaction of the dependent variable has to be considered in econometric analysis by means of existing specific techniques, in order to avoid inefficient and biased estimates. 
Third, attention must be devoted to potential problems concerning the direction of causality and endogeneity of independent variables that may affect the reliability of econometric outcomes. Although we study here the determinants of regional productivity dynamics measured at the beginning of the period, and therefore are statistically predetermined, it is possible that other factors simultaneously influence both productivity growth and its determinants. This would reflect the development of never-ending cycle of causality as in some respects is illustrated in the literature. For example, previous growth rates may influence simultaneously present growth rates (if there is temporal persistence, as happens here), but also attract other firms in search for spillovers, skilled workers looking for higher wages, or foster innovative activities and capital accumulation. Although these complex effects may be weak for the relatively short period considered, the measures of specialization (SPEC), highly skilled human resources (HRST), capital stocks $(C A P)$, and innovation $(I N N)$ were included in the estimates as endogenous. Instead, the remaining variables can be thought of as more closely related to the structural long-term characteristics of the region, and therefore are basically unaffected by subsector specific productivity levels and unrelated to other sector specific features.

3.4.1. Empirical Models and Econometric Approach. For each of the six subsectors, the empirical relationship between productivity growth and its various explanatory variables was estimated by means of panel techniques (151 units, 1995-2004). The empirical literature clearly addresses towards a dynamic specification of the model of productivity growth (i.e., Caselli et al, 1996, Yudong and Weeks, 2000; Carmeci and Mauro, 2003; Esposti and Bussoletti, 2008; Esposti, 2007), in which the dependent variable is regressed against a set of variables measured at the beginning of the period considered and the productivity growth rate of the previous period. The basic sectoral model is therefore a simple AR(1) model (PROD and $C A P$ are measured in logs):

$$
\begin{aligned}
& \Delta P R O D_{r, t}=\alpha_{0}+\alpha_{1}(S P E C)_{r, t-1}+\alpha_{2}\left(S P E C_{m}\right)_{r, t-1}+\alpha_{3}(D E N S)_{r, t-1}+\alpha_{4}\left(D I V_{m}\right)_{r, t-1}+ \\
& \alpha_{5}(H R S T)_{r, t-1}+\alpha_{6}\left(H E T_{d}\right)_{r, t-1}+\alpha_{7}(C A P)_{r, t-1}+\alpha_{8}(I N N)_{r, t-1}+\gamma(P R O D)_{r, t-1}+\rho \Delta P R O D_{r, t-1} \\
& +\tau_{t}+\mu_{r}+\varepsilon_{r, t}
\end{aligned}
$$

where $\triangle P R O D_{\mathrm{r}, \mathrm{t}}=P R O D_{\mathrm{t}}-P R O D_{\mathrm{t}-1}$ is productivity growth, the explanatory variables (defined in section 3.2) are measured at the beginning of the period (year $t-1$ ) and include the level of productivity (convergence/divergence term), and $\rho$ measures the persistence effect (i.e., the possible temporal persistence of productivity growth patterns). The specification also contains, as usual, time effects $(\tau)$, which are common to all regions, and time-invariant unobservable region-specific effects $(\mu) . \varepsilon$ is the error term. The inclusion of the dynamic specification accounts for serial correlation, which may affect productivity growth and also protects against possible inconsistency of estimates due to omitted variable bias. However, the lagged dependent variable is correlated with the error term, i.e., it is endogenous (Arellano, 2003) and an instrumental-variable estimator must be used in order to obtain consistent estimates of parameters. Similar endogeneity questions are posed by other explanatory variables, such as SPEC, HRST, INN, and CAP, as illustrated before. Consistent with recent empirical literature, we employ here the Generalized Method of Moments (GMM) proposed by Arellano and Bond (1991), which is preferable to a simple instrumental variable approach for shallow panels (e.g., Anderson-Hsiao, 1982) The GMM approach used here is the System GMM (GMM-SYS) estimator (Arellano and Bover, 1995; Blundell and Bond, 1998; Roodman, 2006), which is a development of the Difference GMM estimator (GMM-DIFF). The latter requires transforming into first differences the equation to be estimated, because this generates a first-differenced error term $\Delta \varepsilon_{\mathrm{rt}}$ that is uncorrelated with 
the lagged level variables $\left(P R O D_{\mathrm{r}, \mathrm{t}-\mathrm{n}}\right.$, for every $\left.\mathrm{n} \geq 2\right)$. This results in valid instruments. However, Blundell and Bond (1998) explain that the GMM-diff estimator may give rise to marked small-sample bias and the precision of the estimates can tend to decrease in AR(1) specifications whenever the autocorrelation coefficient is close to one. For this reason it is known as the weak instruments problem since the lagged levels may be poor instruments in first difference equations. Therefore, they propose an alternative GMM estimator (GMMsys), where a system of equations is estimated by adding equations in levels to firstdifference equations since, under a mean stationary $\mathrm{AR}(1)$ process, the lagged first difference $\triangle P R O D_{\mathrm{r}, \mathrm{t}-1}$ is uncorrelated with $\varepsilon_{\mathrm{rt}}$ and can therefore be used as a valid instrument for the respective level equation. Here, all available and admitted lagged variables are considered. The consistency of the selection of instruments is assessed by means of an over-identification restriction (Hansen) test. Its null hypothesis is that all the selected instruments are valid (i.e., exogenous) instruments, i.e., uncorrelated with the error term, and that the excluded instruments are correctly excluded from the estimated equation. Therefore, a rejection would cast doubt on the validity of the instruments. We present here two-step GMM estimates: while the one-step estimator also is consistent, the two-step procedure is more efficient (Arellano and Bond, 1991).

Outcomes originating from Equation 9 for the six subsamples are listed in Table 3, which also shows the over-identification restriction test, and first- and second-order serial correlations LM tests in first-differenced residuals proposed by Arellano and Bond (1991). If the AR(1) specification holds true, one should observe first-order serial correlation (generated by first differencing) bur no second-order correlation. In order to account for possible nonlinear relationships, and at the cost of introducing some multicollinearity, the quadratic terms for $S P E C$ and $D E N S$ are also included. The first case checks for the existence of a threshold effect after which specialization produces beneficial/detrimental effects on productivity; similarly, the second case controls for the existence of a possible congestion/urbanization threshold.

A second technical reason that caused us to consider use of GMM-sys relates to the necessity of correcting for possible spatial autocorrelation in the dependent variable. ${ }^{9}$ Hong, Sun, and Li (2008) show that the system GMM method can be employed in order to include simultaneously temporally and spatially lagged dependent variables, and allow for the potential endogeneity of other explanatory variables. Therefore, our empirical model augmented with the spatial autoregressive term is:

$$
\begin{aligned}
& \Delta P R O D_{r, t}=\alpha_{0}+\alpha_{1}(S P E C)_{r, t-1}+\alpha_{2}\left(\operatorname{SPEC}_{m}\right)_{r, t-1}+\alpha_{3}(D E N S)_{r, t-1}+\alpha_{4}\left(D I V_{m}\right)_{r, t-1}+ \\
& \alpha_{5}(H R S T)_{r, t-1}+\alpha_{6}\left(H E T_{d}\right)_{r, t-1}+\alpha_{7}(C A P)_{r, t-1}+\alpha_{8}(I N N)_{r, t-1}+\gamma(P R O D)_{r, t-1}+ \\
& \rho \triangle P R O D_{r, t-1}+\lambda W(\triangle P R O D)_{r, t}+\tau_{t}+\mu_{r}+\varepsilon_{r, t}
\end{aligned}
$$

\footnotetext{
${ }^{9}$ As early as Anselin (1988), the econometric literature shows that traditional spatial autoregressive models may present: (a) the dependent variable correlated with its spatial lag (spatial LAG model); (b) the error term affected by spatial autocorrelation (spatial ERROR model); or (c) both spatial LAG and ERROR correlations. In the first case, a typical omitted-variable problem arises, which cannot be solved by means of OLS estimation (due to simultaneity/endogeneity) and may normally be addressed with maximum likelihood (ML), instrumental variables and robust regression estimates. It is also possible that correcting for the spatial lag of the dependent variable makes the spatial autocorrelation disappear. Methods of estimation alternative to OLS are also recommended in the case of spatial ERROR correlation.
} 
where $\lambda$ is the coefficient of the spatially lagged dependent variable; $W$ is the spatial weights (or spatial lag) matrix; ${ }^{10}$ and with remaining notation as in Equation 9.

3.4.2. Results. The results of the estimation of Equation 9 are shown in Table 3. The outcomes of the specification illustrated in Equation 10 are listed in the Appendix (Table A1) and show, with few exceptions, overall consistency. This general robustness to the inclusion of the spatially lagged dependent variable suggests that information about the spatial structure of regional productivity data was already implicitly included in the first specification, on which we focus our comments (the few differences emerging for the other specification are also listed).

Table 3. Econometric Estimates of Determinants of Labor Productivity Growth (19952004), System GMM, Two Step

\begin{tabular}{|c|c|c|c|c|c|c|}
\hline & DA & DB-DC & DF-DH & DL & $\mathrm{DM}$ & $\mathrm{DD}, \mathrm{E}, \mathrm{N}, \mathrm{I}, \mathrm{J}, \mathrm{K}$ \\
\hline$S P E C$ & $-0.032 * * *$ & $-0.427 * * *$ & $-0.174 * * *$ & $-0.125 * * *$ & $-0.285 * * *$ & $-0.370 * * *$ \\
\hline$S P E C^{2}$ & $0.006 * * *$ & $0.103 * * *$ & $0.044 * * *$ & $0.042 * * *$ & $0.013 * * *$ & $0.108 * * *$ \\
\hline$S P E C \_m$ & $-0.103 * * *$ & $0.017 * *$ & -0.005 & -0.002 & $-0.783^{* * *}$ & $-0.011 * *$ \\
\hline DENS & $-0.014 * * *$ & $-0.072 * * *$ & $-0.015^{* * *}$ & -0.001 & $0.038 * * *$ & $0.002 *$ \\
\hline$D E N S^{2}$ & $0.001 * * *$ & $0.010 * * *$ & $0.002 * * *$ & 0.000 & $-0.006^{* * *}$ & $0.000 * *$ \\
\hline$D I V \_m$ & $0.010 * * *$ & -0.002 & $0.021 * * *$ & $0.012 * * *$ & $0.158 * * *$ & $-0.027 * * *$ \\
\hline$H R S T$ & $-0.009 * * *$ & $0.027 * * *$ & $0.003 * * *$ & $0.002 *$ & $0.126^{* * *}$ & $0.008 * * *$ \\
\hline$H E T \_d$ & $0.022 * * *$ & $0.294 * * *$ & $0.051 * * *$ & $0.029 * * *$ & $0.090 * * *$ & $0.036^{* * *}$ \\
\hline$I N N$ & $-0.006 * * *$ & $0.005 * * *$ & $-0.004 * * *$ & $0.001 * * *$ & $0.001 * * *$ & $0.006 * * *$ \\
\hline ln_CAP & $0.002 * * *$ & $-0.025 * * *$ & $0.005 * * *$ & $0.020 * * *$ & $0.089 * * *$ & $0.002 * *$ \\
\hline $\ln \_P R O D$ & $-0.034 * * *$ & $-0.018 * * *$ & $0.050 * * *$ & $-0.029 * * *$ & $-0.275^{* * *}$ & $0.019 * * *$ \\
\hline$\Delta \ln \_P R O D_{t-1}$ & $0.010 * * *$ & $0.007 * * *$ & $0.015^{* * *}$ & $0.074 * * *$ & $0.039 * * *$ & 0.002 \\
\hline cons & 0.005 & $0.423 * * *$ & $0.034 * * *$ & $0.153 * * *$ & $1.318^{* * *}$ & $0.301 * * *$ \\
\hline \# of observations & 1208 & 1208 & 1208 & 1208 & 1208 & 1208 \\
\hline \# of groups & 151 & 151 & 151 & 151 & 151 & 151 \\
\hline $\begin{array}{l}\text { Wald }\left(\chi^{2}\right)(19) \\
(p \text { value })\end{array}$ & 0.000 & 0.000 & 0.000 & 0.000 & 0.000 & 0.000 \\
\hline Hansen test $\left(\chi^{2}\right)$ & 139.48 & 141.12 & 138.02 & 146.53 & 136.91 & 141.84 \\
\hline AR (1) test & $-3.87 * * *$ & $-3.21 * * *$ & $-3.16^{* * *}$ & $-4.35 * * *$ & $-2.64 * * *$ & $-3.66 * * *$ \\
\hline AR (2) test & -0.50 & -0.20 & 0.37 & -0.95 & 0.86 & -0.59 \\
\hline
\end{tabular}

Note: Time and regions-specific effects included; SPEC, SPEC ${ }^{2}, I N N$, and $\ln \_C A P$ assumed endogenous.

\footnotetext{
${ }^{10}$ The spatial weights (or lag) matrix illustrates the connections between the geographic units in question. Here we use a matrix of the inverse geographical distance between the capital city (or the most highly populated city, when the region is not an administrative unit) of each region.
}

(C) Southern Regional Science Association 2010. 
Before turning our attention to the variables which are the focus of the paper, we provide a few general comments on the signs and significance of the lagged dependent and on the control variables included in the model. First, we observe the overall significant and positive impact of the time lagged dependent variable, which means that labor productivity growth follows cumulative processes and shows path dependence in all sectors. This phenomenon is probably the reason for the remarkable increase in the variability of productivity performances occurring over time, as depicted in Table 1. In four sectors out of six (exceptions are the heavy industry and the other manufacturing sectors), the initial level of labor productivity is negatively related to subsequent growth, i.e., beta convergence in regional productivity occurs. The strength of these convergence patterns is clearly weakened by the positive sign of lagged productivity growth coefficient of the time lagged dependent variable, which, on the contrary, reinforces divergence patterns in DF-DH and DD-DK sectors. Beyond time persistence, productivity growth also shows a space pattern, as testified by the significant and positive coefficients of the spatially lagged dependent variable in Table A1. The two control variables $C A P$ and $I N N$ always assume the expected positive sign, with few exceptions. Also the third control, i.e., the measure of regional manufacturing on total employment $\left(S P E C \_m\right.$ ) has a steadily negative coefficient (the only exception is the textile and clothing sector), suggesting that a strong manufacturing dependency may be associated to regions still linked to traditional industrial activities (or undergoing structural change processes), which may be associated with low growth rates.

As regards our first hypothesis (existence of beneficial effects of homogenous agglomeration patterns and different sectoral strength), the outcomes show a quite complex and partly counterintuitive picture. The many limitations of data available, emphasized in Section 3.1, suggest much caution in interpreting results. Therefore, we consider the evidence provided here as preliminary information to be developed in future empirical studies. Our empirical evidence indicates that $H 1$ is only partly supported. SPEC is indeed significant but negative in all six sectors considered. However, its quadratic term is also significant and positive, and suggests that an inversion of the relationship takes place beyond certain specialization levels, ${ }^{11}$ which is diversified across sectors and falls between 1.4 and 2.5 (with the exception of DM - Transport Equipment - for which the threshold is higher). The many limitations of our empirical work do not encourage attempts to fully explain these complex sectoral outcomes and industry breakdown is too aggregate to venture for explanations of their differences. We only emphasize that the hypothesized beneficial homogenous agglomeration effects come into play only beyond a relatively high (and sectorally different) specialization level. This may suggest that, under the growing competitive pressures exerted by emerging (and partly by transition) countries, very strong sectoral agglomeration patterns only can assure beneficial effects on manufacturing productivity in western regions, i.e., only the most specialized regions are able to produce external economies sufficient to support productivity growth, whereas the remaining regional contexts seem doomed to manufacturing decline.

As regards the various aspects of urban heterogeneous effects, the measure of general science and technology endowments (HSRT) assumes the expected positive sign (the only exception is the DA sector). This seems to support the idea that the size of the scientific and technical human capital of a region (which is normally high in urban areas, although obviously not in all of them) positively affects the productivity dynamic of the units located

\footnotetext{
${ }^{11}$ The threshold at which the change of the relationship takes place can easily be calculated by setting a quadratic function $\left(Y=\alpha X^{2}+\beta X\right)$ at zero; the minimizing value of the $X$ is $X=-\beta / 2 \alpha$. Analytical comparison of subsector thresholds is not possible here, but their ranking is steady for all the econometric specifications adopted.
} 
within it. Econometric estimates also support the view that higher related variety (proxied, in our case, by $D I V \_m$ ) is beneficial to productivity in all sectors; the only exception is subsector DD, the residual one. Interestingly enough, the DENS indicator, once the effects of related diversity and human science and technology resources are controlled for, plays a quite ambiguous role. The sign and significance of the coefficients are relatively unstable in the two specifications of Tables 3 and A1, but the presence of negative coefficients among the significant ones is prevalent. In these cases, the quadratic terms are also significant, but their positive sign and small size only indicate that the negative slope is a decreasing one. Also, in the few cases in which a positive relationship emerges, its strength is be mitigated by nonlinearity. This may indicate that the aspects of urbanity which matter more for productivity are those captured by the presence of highly skilled resources and sector variety; once these aspects are controlled for, simple population or economic activity density plays only a negative or a minor role.

A final comment is devoted to the outcomes of dummy variable HET_d, which identifies regions with high values of DENS, HRST and DIV_m. Its sign is positive in all the sectors in the specifications of Table 3. In the specification with spatial effects (Table A1) the variable loses statistical significance in the first sector (DA). However, we must take into account the fact that, in these estimates, we are already controlling for the three indicators from which it is derived. If we drop DENS, HRTS and DIV_m, the new estimates confirm the steady significance and positive sign of HET_d (Table A $\overline{2}$ in the Appendix), with the only exception DD-DK. In general, these outcomes support the idea that the co-existence of various potential sources of urban assets may be beneficial for productivity.

\section{SUMMARY AND FINAL REMARKS}

This paper aimed at exploring differences in labor productivity growth in manufacturing, focusing on the various factors characterizing the context in which firms are located. More precisely, we examined two types of agglomeration patterns which, respectively, represent homogeneous external economies, stemming from high concentrations of firms in a given manufacturing specialization, and the various sources of urban heterogeneous external economies. In the empirical part of the paper, we test the hypotheses that the two kinds of external economies are beneficial to regional labor productivity dynamics, and that they are not alternative but may co-exist. Empirical analysis is carried out for six manufacturing subsectors of 151 Western European regions, from 1995 to 2004. Data available for analysis of this time and spatial coverage are not optimal to capture the aspects the paper aims to explore: in particular, the empirical analysis suffers from insufficient industry detail and a suboptimal regional unit of analysis. Therefore, outcomes must be considered as initial empirical bases to be developed in future research efforts, better able to address these limitations.

As regards homogeneous agglomeration effects, specialization has a non-linear relationship with productivity growth, and in particular it assumes a U-shape in all six sectors considered. Therefore, homogeneous agglomeration effects but come into play only beyond a relatively high specialization level. The industry breakdown is too coarse for us to go further into interpretations, but suggest that only the highly specialized western EU regions are able to generate and exploit the external homogenous economies that are needed to cope with increasing competitive pressures exerted by emerging and transition countries. As a consequence, manufacturing in regions with low or intermediate specialization seems doomed to decline. In any case, this evidence of an initial negative relationship between regional specialization and productivity needs further investigation. Hopefully it will be carried out using data on the specialization and size distribution of firms over time that are 
more detailed with respect to both industry and geography. This could allow testing an alternative hypothesis for the U-shaped relationship between specialization and productivity growth: that the two stages of the non-linear relationships do correspond to two different stages of agglomeration patterns. The initial one occurs when one or more agglomeration forces encourage highly localized birth/spin-off rates of manufacturing firms (intensive agglomeration stage). Because of their prevalently small size and relative inexperience in specific productive and marketing activities, the resulting new firms may experiment with lower-than-average productivity performance, and this may curb average growth rates of the region. The second one, in which agglomeration forces self-reinforce, market conditions select only the most productive firms, which increase in size (extensive agglomeration stage) and thereby give rise to a positive agglomeration/productivity dynamic.

The picture is quite complex for urban heterogeneous agglomeration effects. Outcomes indicate that regions that are simultaneously densely populated, sectorally diversified, and richly endowed with science and technology resources have higher productivity growth in all manufacturing subsectors. However, important aspects emerge when the three indicators are considered separately. The proxies for endowment of science and technology human resources (HRST) and cross-fertilization among related industries $\left(D I V \_m\right)$ have a steady and generalized positive and significant impact on productivity growth that does not conflict with the impact from specialization. However, the third indicator (DENS), thought to be a proxy of density of economic activity, to sustain local demand, and to increase opportunities for the exchange of information and ideas, has an ambiguous, changing, and persistent negative impact. This implies that among sources of urban heterogeneous economies those that have been associated with densely populated areas are losing momentum. For example, pressures from increasing international competitiveness undoubtedly reduce the role of local demand in orientating productive processes and outcomes; similarly, denser interpersonal links and networks within cities do not influence productivity growth, if they are not specific to a productive activity. Once the variety and intensity of human capital are controlled for, increasing "urbanization" (with no other specific attributes) appears to be disadvantageous, typically via the influence of congestion costs.

\section{REFERENCES}

Ades, Alberto F. and Edward L. Glaeser. (1995) "Trade and Circuses: Explaining Urban Giants," Quarterly Journal of Economics, 110, 195-227.

Anderson, Thoedore W. and Cheng Hsiao. (1982) "Formulation and Estimation of Dynamic Models Using Panel Data," Journal of Econometrics, 18, 47-82

Anselin, Luc. (1988) Spatial Econometrics: Methods and Models. Kluver: Dordrecht.

Arellano Manuel. (2003) Panel-data Econometrics. Advanced Texts in Econometrics. Oxford University Press: Oxford.

Arellano, Manuel and Stephen Bond. (1991) "Some Tests of Specification for Panel-Data: Monte Carlo Evidence and an Application to Employment Equations," Review of Economic Studies, 58, 277-297.

Arellano, Manuel and Olympia Bover. (1995) "Another Look at the Instrumental Variable Estimation of Error-Components Models," Journal of Econometrics, 68, 29-51.

Arrow, Kenneth J. (1962) “The Economic Implications of Learning by Doing," Review of Economic Studies, 29, 155-173.

(C) Southern Regional Science Association 2010. 
Audretsch, David B. (1998) "Agglomeration and the Location of Innovative Activity," Oxford Review of Economic Policy, 14, 18-29.

Audretsch, David B. and Maryann P. Feldman. (2004) "Knowledge Spillovers and the Geography of Innovation," in J. Vernon Henderson, and Jacques-François Thisse, eds, Handbook of Regional and Urban Economics, Vol. 4. North Holland: Amsterdam, pp. 2713-2739.

Becattini, Giacomo. (2004) Industrial Districts: A New Approach to Industrial Change. Edward Elgar: Cheltenham, U.K.

Becattini, Giacomo and Francesco Musotti. (2003) "Measuring the District Effect. Reflections on the Literature," Banca Nazionale del Lavoro Quarterly Review 56, 259-290.

Bellandi, Marco. (2004) "Sistemas Productivos Locales y Bienes Publicos Especificos," Ekonomiaz, Basque Economics Journal (Revista Vasca de Economia), 53, 51-73.

Begg, Iain. (2002) Urban Competitiveness. Policies for Dynamic Cities. The Policy Press: Bristol, U.K.

Benito, Juan M. and Roberto Ezcurra. (2005) "Spatial Disparities in Productivity and Industry Mix: the Case of the European Regions," European Urban and Regional Studies, 12, 177-194.

Boschma, Ron A. and Simona Iammarino. (2007) "Related Variety and Regional Growth in Italy.” SPRU Working Papers Series 162: Brighton, UK.

Blundell, Richard and Stephen Bond. (1998) "Initial Condition and Moment Restrictions in Dynamic Panel Data Models," Journal of Econometrics, 68, 29-51.

Bracalente, Bruno and Cristiano Perugini. (2010) "The Components of Regional Disparities in Europe," Annals of Regional Science, in press (doi: 10.1007/s00168-008-0276-1).

Carmeci, Gaetano and Luciano Mauro. (2003) "Imperfect Labor Market and Convergence: Theory and Evidence for Some OECD Countries," Journal of Policy Modeling, 25, $837-856$.

Caselli, Francesco, Gerardo Eequivel, and Fernando Lefort. (1996) "Reopening the Convergence Debate: a New Look at Cross Country Growth Empirics," Journal of Economic Growth, 1, 363-389.

Cingano, Federico and Fabiano Schivardi. (2004) "Identifying the Sources of Local Productivity Growth," Journal of the European Economic Association, 2, 720-742.

Cossentino, Francesco, Frank Pyke, and Werner Sengenberger (eds). (1996). Local and Regional Response to Global Pressure: the Case of Italy and its Industrial Districts. International Institute of Labour Studies: Geneva.

Davis, James C. and J. Vernon Henderson. (2003) "Evidence on the Political Economy of the Urbanization Process," Journal of Urban Economics, 53, 98-125

Duranton, Gilles and Diego Puga. (2001) "Nursery Cities: Urban Diversity, Process Innovation, and the Life Cycle of Products," American Economic Review, 91, 14541475.

Ejermo, Olof. (2005) “Technological Diversity and Jacobs' Externality Hypothesis Revisited," Growth and Change, 36, 167-195.

(C) Southern Regional Science Association 2010. 
Esposti, Roberto. (2007) "Regional Growth and Policies in the European Union: Does the Common Agricultural Policy Have a Counter-Treatment Effect," American Journal of Agricultural Economics, 89, 116-134

Esposti, Roberto and Stefania Bussoletti. (2008) "Impact of Objective 1 Funds on Regional Growth Convergence in the European Union: a Panel Data Approach," Regional Studies, 42, 159-173

Ezcurra, Roberto, Edro Pascual, and Manuel Rapun. (2006) "The Dynamics of Industrial Concentration in the Regions of the European Union," Growth and Change, 37, 200229.

Feldman, Maryann P. and David B. Audretsch. (1999) "Innovation in Cities: Science-Based Diversity, Specialization and Localized Competition," European Economic Review, 43, 409-429.

Frenken, Koen, Frank G. Van Oort, and Thijs Verburg. (2007) "Related Variety, Unrelated Variety and Regional Economic Growth," Regional Studies, 41, 685-697.

Fuà, Giorgio. (1988) "Small-scale Industry in Rural Areas: the Italian Experience," in Kenneth J. Arrow, ed., The Balance between Industry and Agriculture in Economic Development. Macmillan and I.E.A: London, pp. 259-279.

Fujita, Masahisa, and Jacques-François Thisse. (2002) Economics of Agglomeration: Cities, Industrial Location, and Regional Growth. Cambridge University Press: Cambridge, U.K.

Harhoff, Dietmar, Narin Francis, Frederic M. Scherer, and Katrin Vopel. (1999) "Citation Frequency and the Value of Patented Inventions," Review of Economics and Statistics, 81, 511-515

Gardiner, Ben, Ron Martin, and Peter Tyler. (2004) "Competitiveness, Productivity and Economic Growth across European Regions,” Regional Studies, 38, 1045-1067.

Glaeser, Edward L., Heidi D. Kallal, Jose A. Scheinkman, and Andrei Shleifer. (1992) "Growth in Cities," Journal of Political Economy, 100, 1126-1152.

Groningen Growth and Development Center (GGDC), 60-Industry Database, October 2005. Available at: http://www.ggdc.net.

Guiso, Luigi, and Fabiano Schivardi. (2006) "Spillovers in Industrial Districts," Economic Journal, 117, 68-93.

Harrison, Bennet, Maryellen R. Kelley, and Jon Gant. (1996) "Innovative Firm Behavior and Local Milieu: Exploring the Intersection of Agglomeration, Firm Effects, and Technological Change," Economic Geography, 72, 233-258.

Henderson, J. Vernon. (1986) "Efficiency of Resource Usage and City Size," Journal of Urban Economics, 19, 47-70.

(2007) "Understanding Knowledge Spillovers," Regional Science and Urban Economics, 37, 497-508.

Hoover, Edgar M. (1937) Location Theory and the Shoe and Leather Industry. Harvard University Press: Cambridge, MA. (1948) The Location of Economic Activity. McGraw Hill: New York.

Hong, Eunsuk, Sun Laixuang, and Tao Li. (2008) "Location of Foreign Direct Investment in China: A Spatial Dynamic Panel Data Analysis by Country of Origin," The Center for

(C) Southern Regional Science Association 2010. 
Financial and Management Studies Discussion Paper 86, University of London: London, U.K.

Jacobs, Jane. (1969) The Economy of Cities. Vintage: New York.

. (1984) Cities and the Wealth of Nations: Principles of Economic Life. Vintage: New York.

Jaffe, Adam B. and Joshua Lerner. (2004) Innovation and Its Discontents. Princeton University Press: Princeton, NJ.

Jaffe, Adam B., Manuel Trajtenberg, and Rebecca Henderson. (1993) "Geographic Localization of Knowledge Spillovers as Evidenced by Patent Citations," Quarterly Journal of Economics, 108, 577-598.

Kolko, Jed. (1999) "Can I Get Some Service Here? Information Technology Service Industries, and the Future of Cities." Available at SSRN: http://ssrn.com/abstract $=985712$.

Krugman, Paul. (1990) The Age of Diminished Expectations. MIT Press: Cambridge, MA. . (1991a). Geography and trade. MIT Press: Cambridge, MA.

. (1991b) "Increasing Returns and Economic Geography," Journal of Political Economy, 99, 484-499.

Lucas, Robert E. Jr. (1988) "On the Mechanics of Economic Development," Journal of Monetary Economics, 22, 3-42.

Marshall, Alfred. (1920) Principles of Economics. Macmillan: London.

Martino, Gaetano and Cristiano Perugini. (2007) "Towards an Interpretation of Economic Inequality in Rural Areas: a Conceptual and Empirical Approach," SR /Italian Journal of Regional Science, 6, 61-90.

Moreno, Rosina, Paci Raffaele and Stefano Usai. (2005) "Geographical and Sectoral Clusters of Innovation in Europe," Annals of Regional Science, 39, 715-739

Murdoch, Jonathan. (2000) "Networks: a New Paradigm of Rural Development," Journal of Rural Studies, 16, 407-419.

OECD. (1994) Creating Rural Indicators. OECD: Paris.

Paci, Raffaele and Stefano Usai. (1999) "Externalities, Knowledge Spillovers and the Spatial Distribution of Innovation," GeoJournal, 49, 381-390.

(2006) "Agglomeration Economies and Growth. The Case of Italian Local Labor Systems, 1991-2001.” CRENoS Working Paper 12, Centre for North South Economic Research, University of Cagliari and Sassari: Sardinia, Italy.

Perugini, Cristiano and Pierluigi Daddi. (2005) "Il Ruolo delle Economie Esterne nella Performance Competitiva dell'Industria Manifatturiera Italiana. Un'Analisi dell'Export a Livello Territoriale," Economia, Società, Istituzioni, 17, 9-45.

Porter, Michael E. (1990) The Competitive Advantage of Nations. Free Press: New York. . (2003) “The Economic Performance of Regions,” Regional Studies, 37, 549-578.

Rauch, James. (1991) "Productivity Gains from Geographical Concentration of Human Capital: Evidence from Cities." National Bureau of Economic Research Working Paper 3905: Cambridge, Massachusetts.

(C) Southern Regional Science Association 2010. 
Roodman, David. (2006) "How to Do Xtabond2: An Introduction to "Difference" and "System" GMM in Stata." Center for Global Development Working Papers 103.

Romer, Paul M. (1986) "Increasing Returns and Long-Run Growth," Journal of Political Economy, 94, 1002-1037.

Schmoch, Ulrich, Laville Francoise, Pari Patel, and Rainer Frietsch. (2003) Linking Technology Areas to Industrial Sectors. Final Report to the European Commission, DG Research, Fraunhofer-ISI, OST, SPRU. Available at: $\mathrm{ftp} / / / \mathrm{ftp} . c o r d i s . e u r o p a . e u / p u b /$ indicators/docs/ind_report_isi_ost_spru.pdf

Sørensen, Anders. (2001) "Comparing Apples to Oranges: Productivity Convergence and Measurement across Industries and Countries: Comment," American Economic Review, 91, 1160-1167.

John, Caron H. and Richard W. Pouder. (2006) "Technology Clusters versus Industry Clusters: Resources, Networks, and Regional Advantages," Growth and Change, 37, $141-171$

Tabuchi, Takatoshi and Atsushi Yoshida. (2000) "Separating Urban Agglomeration Economies in Consumption and Production," Journal of Urban Economics, 48, 7084.

Turok, Ivan N. (2004) “Cities, Regions and Competitiveness,” Regional Studies, 38, 10691083.

Van Zeebroeck, Nicolas. (2007) "The Puzzle of Patent Value Indicators." Working Paper CEB 07-023: Université Libre de Bruxelles.

Von Hipple, Eric. (1994) "Sticky Information and the Locus of Problem Solving: Implications for Innovation,” Management Science, 40, 429-439.

Wheeler, Christopher H. (2005) "Cities, Skills, and Inequality," Growth and Change, 36, 329-353.

Yudong, Yao and Melvyn Weeks. (2000) "Provincial Income Convergence in China, 19531997: A Panel-Data Approach," Econometric Reviews, 22, 59-77.

(C) Southern Regional Science Association 2010. 


\section{APPENDIX}

TABLE A1. Estimates of Determinants of Labor Productivity Growth (1995-2004), System GMM with Time- and Space-lagged Dependent (Two Step)

\begin{tabular}{|c|c|c|c|c|c|c|}
\hline & DA & DB-DC & DF-DH & DL & $\mathrm{DM}$ & $\mathrm{DD}, \mathrm{E}, \mathrm{N}, \mathrm{I}, \mathrm{J}, \mathrm{K}$ \\
\hline SPEC & $-0.034 * * *$ & $-0.397 * * *$ & $-0.170 * * *$ & $-0.084 * * *$ & $-0.140 * * *$ & $-0.404 * * *$ \\
\hline$S P E C^{2}$ & $0.007 * * *$ & $0.099 * * *$ & $0.041 * * *$ & $0.027 * * *$ & $0.002 * * *$ & $0.130 * * *$ \\
\hline$S P E C_{-} m$ & $-0.106 * * *$ & 0.010 & 0.000 & $0.008 * * *$ & $-0.386 * * *$ & $-0.008 * * *$ \\
\hline DENS & $-0.018 * * *$ & $-0.046^{* * *}$ & $-0.012 * * *$ & $-0.008 * * *$ & 0.004 & -0.003 \\
\hline$D E N S^{2}$ & $0.001 * * *$ & $0.007 * * *$ & $0.002 * * *$ & $0.001 * * *$ & -0.001 & 0.000 \\
\hline$D I V \_m$ & $0.008 * * *$ & $0.005 * * *$ & $0.016^{* * *}$ & $0.005 * * *$ & $0.061 * * *$ & $-0.025 * * *$ \\
\hline$H R S T$ & $-0.014 * * *$ & $0.028 * * *$ & $0.004 * * *$ & 0.000 & $0.070 * * *$ & $0.004 * * *$ \\
\hline$H E T \_d$ & 0.006 & $0.220 * * *$ & $0.042 * * *$ & $0.034 * * *$ & $0.066 * * *$ & $0.036 * * *$ \\
\hline$I N N$ & $0.002 * * *$ & $0.005 * * *$ & $-0.005 * * *$ & $0.001 * * *$ & $0.001 * * *$ & $0.010 * * *$ \\
\hline $\ln \_C A P$ & $0.005 * * *$ & $-0.024 * * *$ & $0.004 * * *$ & $0.007 * * *$ & $0.033 * * *$ & $0.007 * * *$ \\
\hline ln_PROD & $-0.033 * * *$ & $-0.014 * * *$ & $0.059 * * *$ & $-0.032 * * *$ & $-0.157 * * *$ & $0.026^{* * *}$ \\
\hline$\Delta l n_{-} P R O D_{t-1}$ & $0.007 * * *$ & $0.023 * * *$ & 0.003 & $0.004 * *$ & $0.029 * * *$ & $0.026 * * *$ \\
\hline$W \ln _{-} P R O D_{t}$ & $0.960 * * *$ & $0.247 * * *$ & $0.354 * * *$ & $1.069 * * *$ & $0.054 * * *$ & $0.836^{* * *}$ \\
\hline cons & 0.004 & $0.369 * * *$ & $-0.029 * * *$ & $-0.064 * * *$ & $0.879 * * *$ & $0.301 * * *$ \\
\hline \# of observations & 1208 & 1208 & 1208 & 1208 & 1208 & 1208 \\
\hline \# of groups & 151 & 151 & 151 & 151 & 151 & 151 \\
\hline $\begin{array}{l}\text { Wald }\left(\chi^{2}\right)(20) \\
\left(p \_ \text {value }\right)\end{array}$ & 0.000 & 0.000 & 0.000 & 0.000 & 0.000 & 0.000 \\
\hline Hansen test $\left(\chi^{2}\right)$ & 131.84 & 135.01 & 137.03 & 134.57 & 143.22 & 136.49 \\
\hline AR (1) test & $-3.98 * * *$ & $-3.20 * * *$ & $-3.09 * * *$ & $-4.10 * * *$ & $-2.64 * * *$ & $-3.86^{* * *}$ \\
\hline AR (2) test & -0.52 & -0.02 & 0.34 & -1.50 & 0.82 & -0.30 \\
\hline
\end{tabular}

Note: Time and regions-specific effects included; SPEC, SPEC ${ }^{2}$, INN and $l n \_C A P$ assumed endogenous

(C) Southern Regional Science Association 2010. 
TABLE A2. Econometric Estimates of Determinants of Labor Productivity Growth (1995-2004), System GMM (two step)

\begin{tabular}{|c|c|c|c|c|c|c|}
\hline & $\mathrm{DA}$ & DB-DC & DF-DH & DL & $\mathrm{DM}$ & DD,E,N,I,J,K \\
\hline SPEC & $-0.014 * * *$ & $-0.704 * * *$ & $-0.180 * * *$ & $-0.124 * * *$ & $-0.477 * * *$ & $-0.463 * * *$ \\
\hline$S P E C^{2}$ & $0.003 * * *$ & $0.194 * * *$ & $0.048 * * *$ & $0.041 * * *$ & $0.056 * * *$ & $0.178 * * *$ \\
\hline$S P E C \_m$ & $-0.008 * * *$ & $0.069 * * *$ & $-0.005 * * *$ & $0.008 * * *$ & -0.026 & $-0.051 * * *$ \\
\hline$H E T \_d$ & $0.005^{* * *}$ & $0.224 * * *$ & $0.140 * * *$ & $0.031 * * *$ & $0.117 * * *$ & 0.001 \\
\hline$I N N$ & $0.003 * * *$ & $0.006 * * *$ & $-0.003 * * *$ & $0.001 * * *$ & $0.000 * * *$ & $0.013 * * *$ \\
\hline $\ln \_C A P$ & $0.003 * * *$ & $-0.040 * * *$ & $0.016 * * *$ & $0.012 * * *$ & $0.073 * * *$ & $0.004 * * *$ \\
\hline ln_PROD & $-0.019 * * *$ & $-0.035 * * *$ & $0.038 * * *$ & $-0.026 * * *$ & $-0.317 * * *$ & $0.014 * * *$ \\
\hline$\Delta l n_{-} P R O D_{t-1}$ & $0.067 * * *$ & $0.009 * * *$ & $0.018 * * *$ & $0.076^{* * *}$ & $0.072 * * *$ & $0.037 * * *$ \\
\hline constant & $-0.044 * * *$ & $0.520 * * *$ & $-0.036 * * *$ & $0.064 * * *$ & $1.256 * * *$ & $0.285 * * *$ \\
\hline$N$. observations & 1,208 & 1,208 & 1,208 & 1,208 & 1,208 & 1,208 \\
\hline$N$. groups & 151 & 151 & 151 & 151 & 151 & 151 \\
\hline $\begin{array}{l}\text { Wald }(\chi 2)(19) \\
(p \text { value })\end{array}$ & 0.000 & 0.000 & 0.000 & 0.000 & 0.000 & 0.000 \\
\hline Hansen test $\left(\chi^{2}\right)$ & 144.84 & 96.24 & 124.69 & 149.00 & 102.26 & 138.16 \\
\hline AR (1) test & $-3.86 * * *$ & $-3.20 * * *$ & $-3.22 * * *$ & $-4.33 * * *$ & $-2.62 * * *$ & $-3.72 * * *$ \\
\hline AR (2) test & -0.06 & -0.39 & 0.49 & -0.92 & 1.25 & -0.30 \\
\hline
\end{tabular}

Note: Time and regions-specific effects included; SPEC, SPEC ${ }^{2}, I N N$ and (In)CAP assumed endogenous 
FIGURE A1. Labor Productivity (PROD) Distributions in the 151 EU Regions, by Manufacturing Subsectors

Food, Beverages and Tobacco (DA)

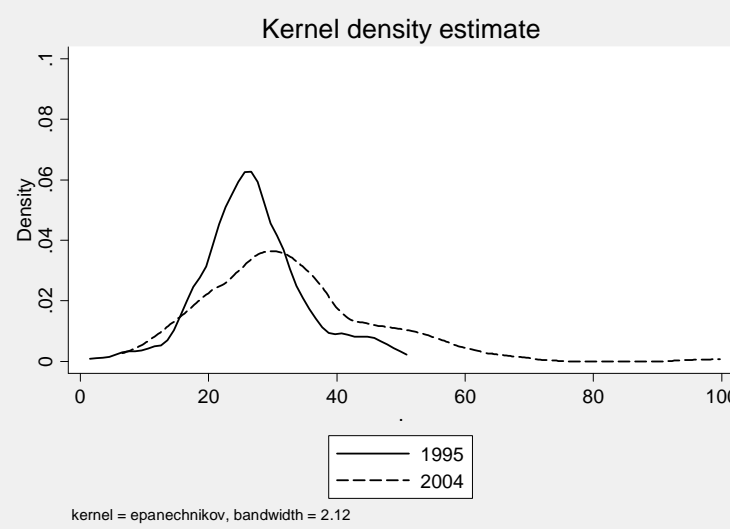

Textiles and Clothing (DB,DC)

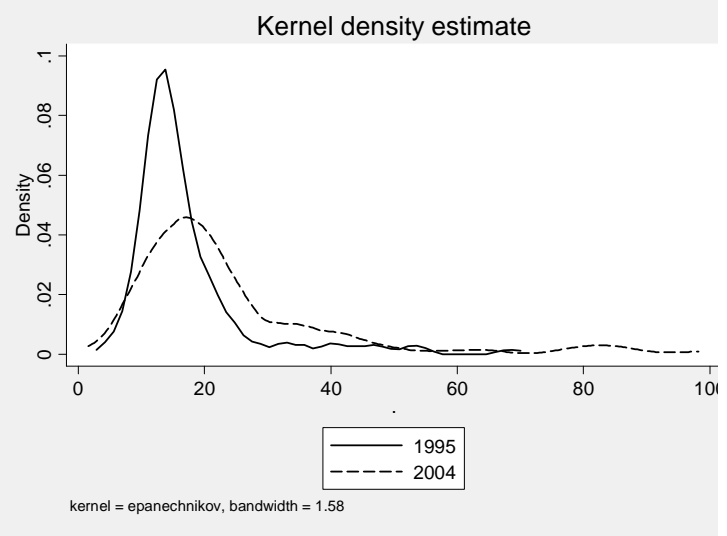

Fuels, Chemicals, Rubber and Plastic Electronics (DL)

Products (DF-DH)
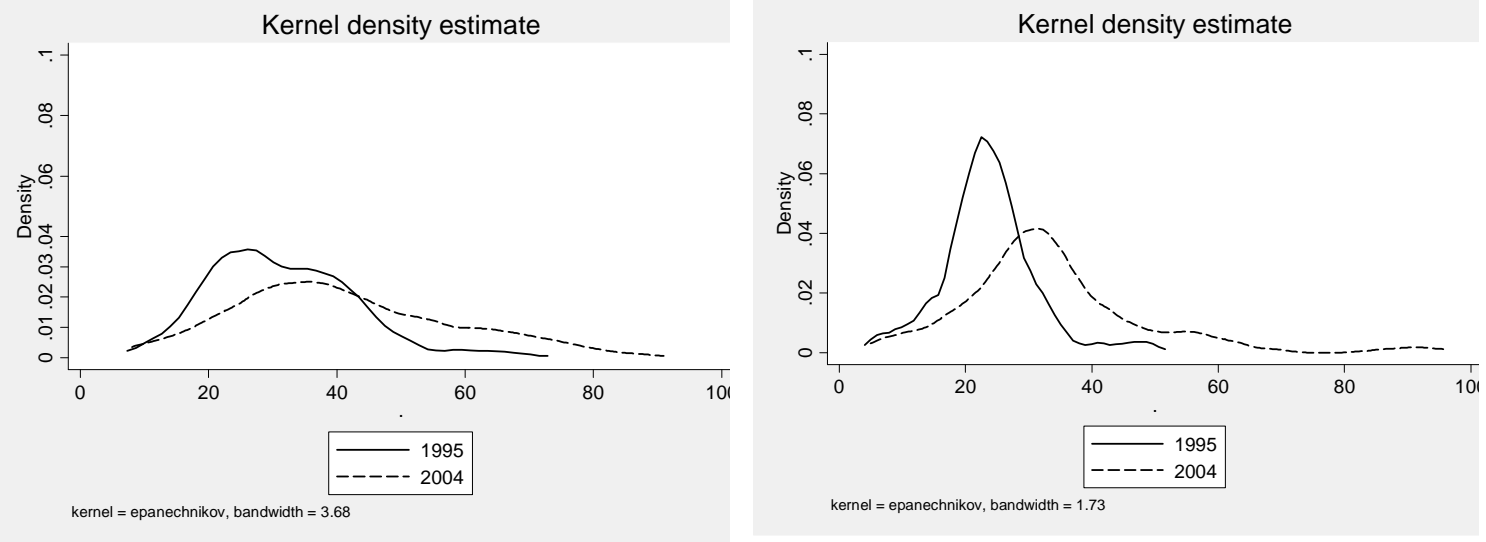

Transport Equipment (DM)

Other Manufacturing (DD-E-N-I-J-K)
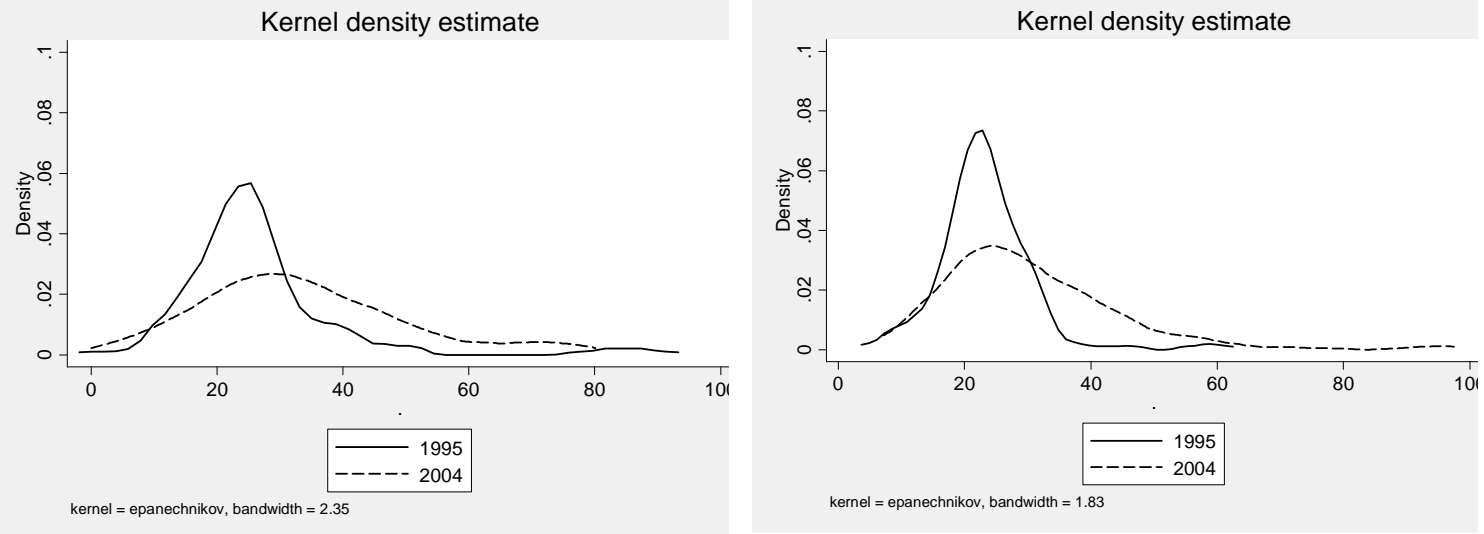

(C) Southern Regional Science Association 2010. 
FIGURE A2. Distributions of the Levels of Specialization (SPEC) of the 151 EU Regions in the Manufacturing Subsectors

Food, Beverages and Tobacco (DA)

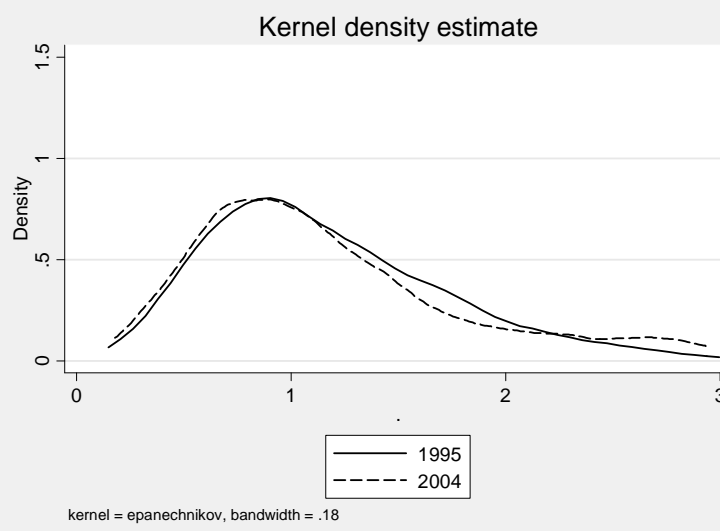

Textiles and Clothing (DB,DC)

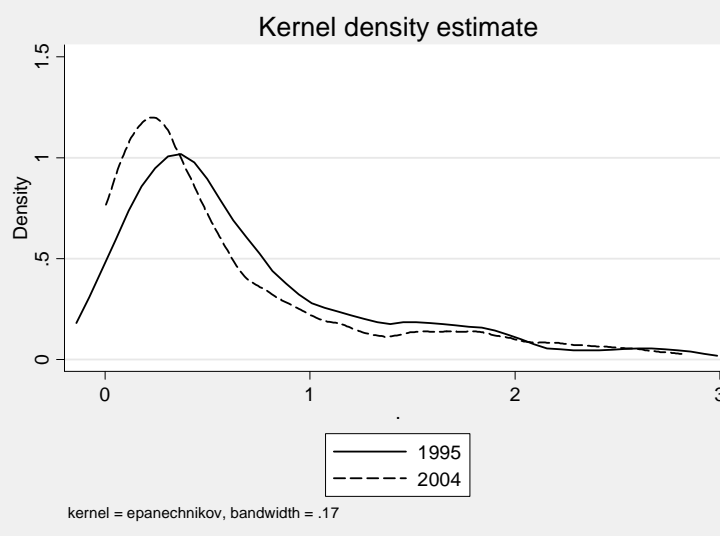

Fuels, Chemicals, Rubber and Plastic Electronics (DL) Products (DF-DH)
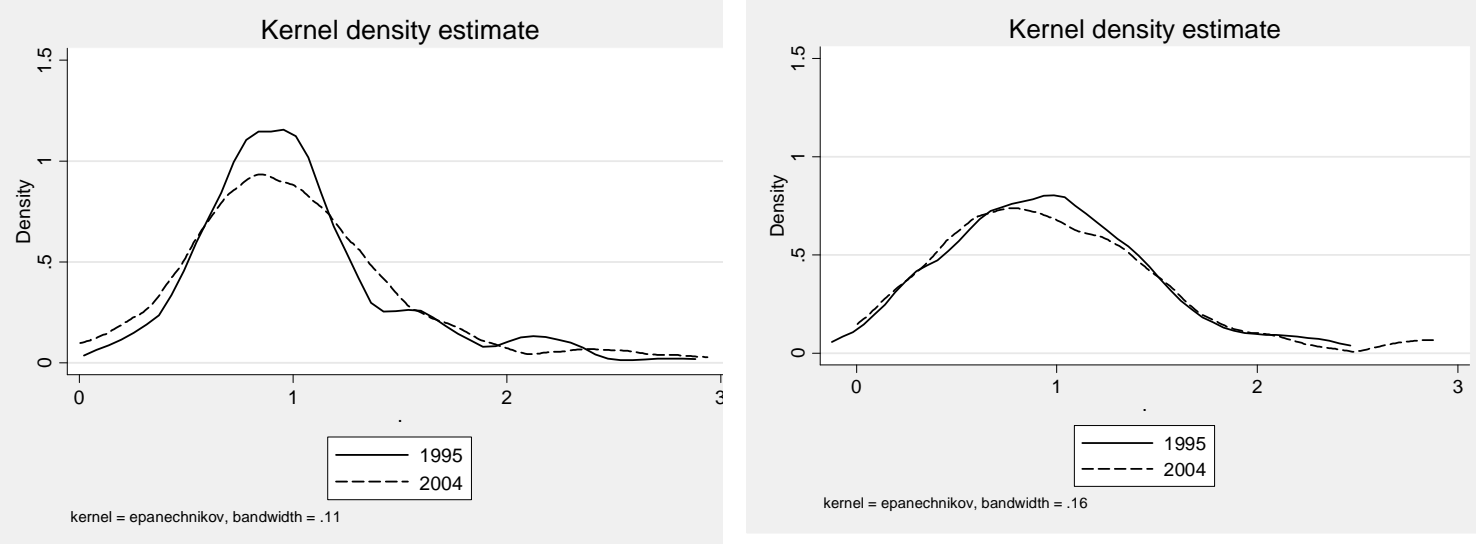

Transport Equipment (DM)

Other Manufacturing (DD-E-N-I-J-K)
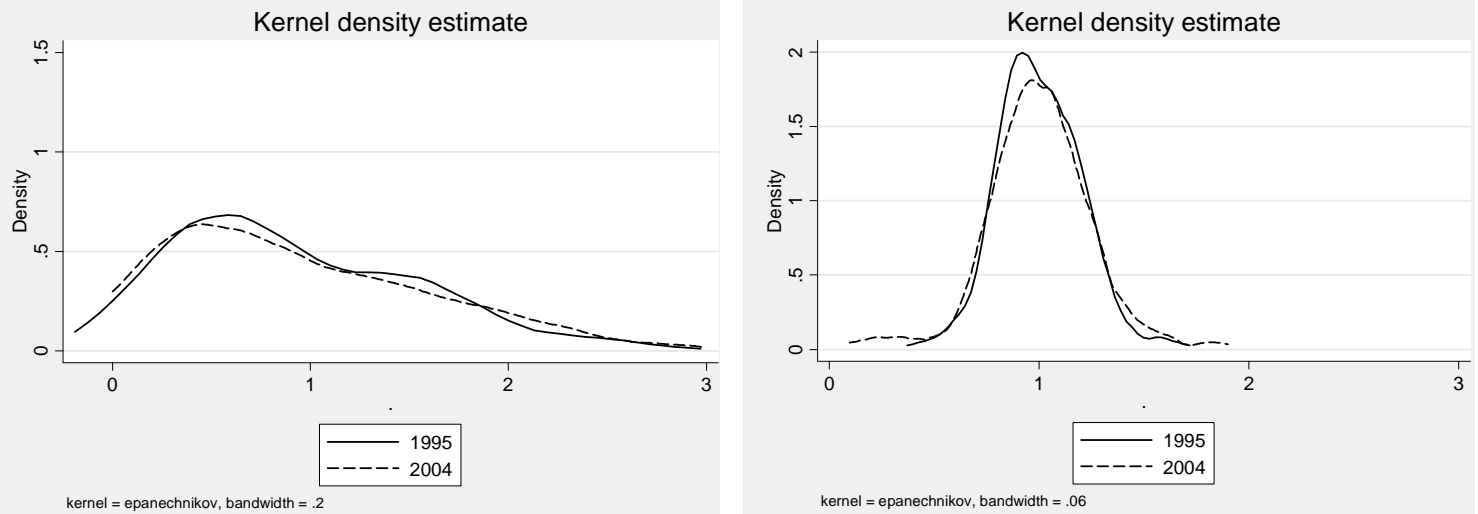

(C) Southern Regional Science Association 2010. 
FIGURE A3. Distributions of the Urban Heterogeneity Indicators (DENS, DIV_m, HRST) of the 151 EU Regions

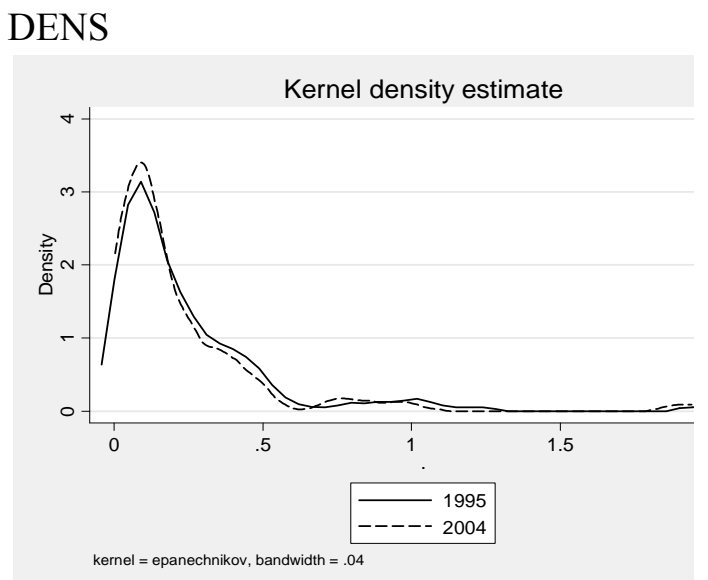

$$
\text { DIV_m }
$$

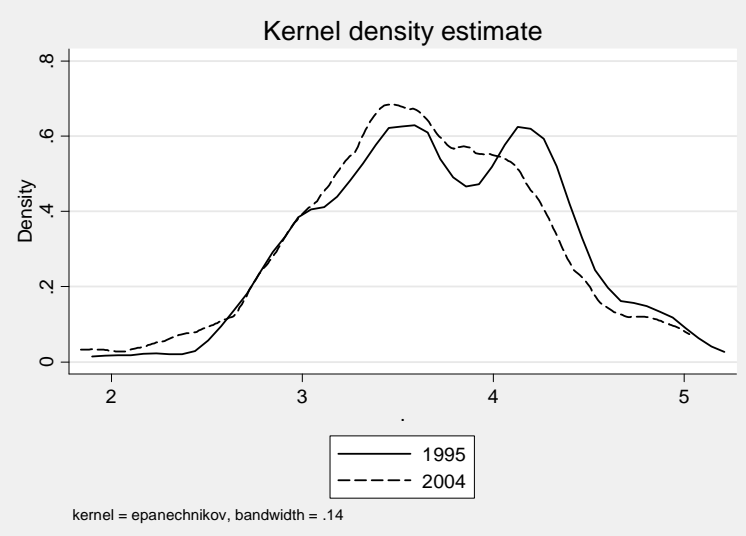

HRST

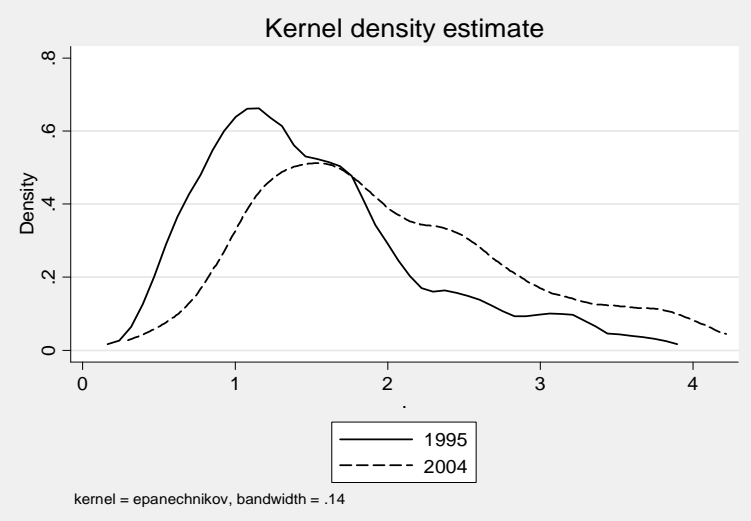

(C) Southern Regional Science Association 2010. 